\title{
Income Distribution and Trade Pattern
}

\author{
Sugata Marjit \\ Indian Institute of Foreign Trade, India, and CES-ifo, Germany \\ Reza Oladi* \\ Department of Applied Economics, Utah State University, USA \\ Punarjit Roychowdhury \\ Business School, University of Nottingham , UK
}

Revised: September 2019

\begin{abstract}
Motivated by recent insights from behavioral economics and social psychology, we present a theory of trade that seeks to explain inter-industry trade between countries that are similar in their production sides, but differ in their income distribution. By assuming status-dependent preferences that are non-homothetic, we show that income inequality differential can be a basis for inter-industry trade between otherwise similar economies.
\end{abstract}

JEL: F11

Keywords: Inequality and trade, non-homothetic preferences, social status

\footnotetext{
${ }^{*}$ Correspondence: Reza Oladi, Department of Applied Economics, Utah State University, 4835 Old Main Hill, Logan, UT 84322-4835. Tel: 435-797-8196. E-mail: reza.oladi@usu.edu. We are thankful to two anonymous referees for their constructive comments and suggestions. Marjit and Roychowdhury gratefully acknowledge financial support from the Centre for Training and Research in Public Finance and Policy, India and RBI endowment at the Centre for Studies in Social Sciences, India. Oladi acknowledges support from Utah Agricultural Experiment Station. All remaining errors are our own.
} 


\title{
Income Distribution and Trade Pattern
}

\begin{abstract}
Motivated by recent insights from behavioral economics and social psychology, we present a theory of trade that seeks to explain inter-industry trade between countries that are similar in their production sides, but differ in their income distribution. By assuming status-dependent preferences that are non-homothetic, we show that income inequality differential can be a basis for inter-industry trade between otherwise similar economies.
\end{abstract}

\section{Introduction}

Classical and neoclassical trade theory posits differences in relative factor endowments across countries as the basis for international trade (see Jones, 1965). Empirical studies, however, reveal that the bulk of world trade takes place between 'similar' countries, i.e., countries that virtually have no supply side differences. This has been noted by Krugman (1979) and Grossman and Rossi-Hansberg (2012), among others. In this paper, based on recent insights from behavioral economics and social psychology, we develop a simple theory to explain trade between countries with identical factor endowments by focusing on the role of income distribution. Specifically, we construct a 'behavioral' version of the Heckscher-Ohlin model involving two countries, two factors of production, and two goods: a status good whose consumption is, at least, partly driven by the prestige value associated with it (e.g., branded clothing) and a non-status good which has no prestige value (e.g., non-branded clothing). We show how differences in preexisting levels of income inequality across countries may potentially determine the pattern of international trade when individuals have status dependent preferences that are non-homothetic.

Previous studies that seek to explain trade between countries with similar factor endowments emphasize either on increasing returns to scale and product differentiation (e.g., Krugman, 1979, and Helpman, 1981) or on technological differences across countries (e.g., Davis, 1998). These papers assume preferences to be strictly homothetic and focus solely on the production sides of economies. However, some empirical findings provide compelling evidence that preferences may not be homothetic (e.g., see Thursby and Thursby, 1987). Studies that systematically incorporate non-homotheticity preferences offer a strictly demand-side explanation for a range of phenomenon like home bias in consumption, the mystery of missing trade and volume of trade include Markusen (1986), Hunter (1991), and Mitra and Trindade (2005), among a few others. While a few of these studies have considered the role of income distribution in international trade (e.g., Mitra and Trindade, 2005), none have specifically explored the link between inequality and 
trade involving status goods from a 'behavioral' perspective, as we do. ${ }^{1}$ While there may be disagreement on measurement of inequality in the literature, we use the simplest definition (i.e., the percentage of earned income) ${ }^{2}$

\section{The Model}

There are two goods, a status good $(S)$ and a non-status good $(N)$. There are also two factors of production, capital and labor denoted by $K$ and $L$, respectively. We impose all neoclassical assumptions, including constant returns to scale, on production functions for $S$ and $N$. Further, we assume that $S$ is a capital intensive good, there is no factor intensity reversal, and all markets are perfectly competitive.

Individuals (indexed by subscript $i$ ) care not only about absolute consumption of the two goods but are also concerned with their social status, which is now widely recognized by behavioral economists as one of the key motivations in human behavior (for example, see Weiss and Fershtmen, 1998). Social status confers psychological rewards like self esteem and sense of power (Rucker and Galinsky, 2008). Following Clark et al. (2008), we define social status of an individual $i$, denoted by $\Lambda_{i}$, as the income of individual $y_{i}$ relative to the average income in the economy $\bar{y}$. That is,

$$
\Lambda_{i}=\frac{y_{i}}{\bar{y}}
$$

Clearly, the higher (lower) is an individual's income relative to the average income, the greater (lower) is her social status.

To formally characterize the behavior of individuals, we invoke two axioms based on recent insights from behavioral economics and social psychology. Our first axiom addresses how concern for social status affects wellbeing of individuals. Towards that end, we note recent empirical findings suggesting that an increase in status does not result in an 'equal' increase in wellbeing of all individuals across income distribution. Specifically, using a micro panel data from Germany, Ferrer-i-Carbonell (2005) finds robust evidence that "poorer individuals well-being is negatively influenced by the fact that their income is lower than that of their reference group, while richer

\footnotetext{
${ }^{1}$ Our paper is related to Grossman and Shapiro (1988) that considers trade in status goods. However, the issue that they are concerned with is foreign counterfeiting of such goods which is tangentially related to this note. Our paper is also related to Chakrabarti (2000) and Pi and Zhou (2015). These papers examine the impact of international trade on inequality. We, instead, focus on the converse relationship.

${ }^{2}$ See Cowell and Flachaire (2017) for various measurements of inequality.
} 
individuals do not get happier from having an income above the average." Similar findings have also been reported by Blanchflower and Oswald (2004). These findings are in congruence with the predictions of Duesenberry (1949), Hollander (2001), and Frank (1985) that income comparisons are asymmetric and seem to suggest that the psychological rewards that status confers is important for wellbeing of those who belong to the lower end of the social ladder, but not important for those who belong to the higher end. This observation leads to our first axiom:

Axiom 1. 'Falling behind' hurts: having less income below the average level in a society reduces individual utility but having more income above the average does not matter.

Our next axiom has to do with an individual's tendency toward substituting status good rather for non-status good. In a recent study, Sivanathan and Petit (2010) note that, since lack of status psychologically hurts those who 'fall behind' and may induce chronic 'self-threat' among them, these individuals are likely to seek indirect opportunities to compensate for the loss of happiness and to restore their self worth. They hypothesize that one indirect route through which the individuals who fall behind attempt to restore self-worth could be by consuming status infused goods. The argument is that given the intimate connection between self and possessions (Beggan, 1992), consumption of status goods can potentially serve as an indirect source of selfaffirmation for wounded egos (i.e., those who are psychologically hurt from not being able to keep up with the rest). In order to test this hypothesis, Sivanathan and Petit (2010) carry out a series of laboratory and field experiments. Strikingly, they find strong evidence in favor of their hypothesis. Specifically, they find that threatened individuals seek out status goods to soothe their psychological pain and that consumption of such goods is, at least partially, motivated by their bruised self esteem. ${ }^{3}$ Thus, we have our second axiom as follows:

Axiom 2. 'Falling behind' increases the marginal rate of substitution for the status to non-status goods.

That is, people with lower than average income are willing to give up more of the non-status good to consume an extra unit of the status good.

Based on the above axioms we devise the following utility function to represent the preferences of a representative individual $i$ :

$$
U\left(N_{i}, S_{i}, \Lambda_{i}\right)=f\left(\Lambda_{i}\right)\left[\log N_{i}+\phi\left(\Lambda_{i}\right) \log S_{i}\right]
$$

\footnotetext{
${ }^{3}$ Note that this explanation of status consumption is an alternative to the 'wealth signaling' explanation of this phenomenon (see Dwibedi and Marjit (2017).
} 
where $f\left(\Lambda_{i}\right)<1, \forall \Lambda_{i}<1$, and $f\left(\Lambda_{i}\right)=1, \forall \Lambda_{i} \geq 1$. Also, we assume that $\phi\left(\Lambda_{i}\right)>1, \forall \Lambda_{i}<1$, and $\phi\left(\Lambda_{i}\right)=1, \forall \Lambda_{i} \geq 1$. Moreover, we assume $f^{\prime}\left(\Lambda_{i}\right)>0, \forall \Lambda_{i}<1$ (Axiom 1 ), and $\phi^{\prime}\left(\Lambda_{i}\right)<0, \forall \Lambda_{i}<1$ (Axiom 2). For sake of tractability, we shall assume for $\Lambda_{i}<1, f\left(\Lambda_{i}\right)=\Lambda_{i}$ and $\phi\left(\Lambda_{i}\right)=1 / \Lambda_{i}{ }^{4}$ Note that the utility function that we have developed is non-homothetic as long as income inequality is non-zero. ${ }^{5}$

We assume that the economy consists of two homogeneous groups of people, each with unity mass: the rich and the poor, denoted by $R$ and $P$, respectively. The share of $R$ in the economy's labor and capital stock is $\sigma$, where $\sigma \in[1 / 2,1]$. Then, this share for group $P$ is $1-\sigma$. Thus, incomes of the groups $R$ and $P$ are respectively given by:

$$
y^{R}=\sigma(w \bar{L}+r \bar{K}), \quad y^{P}=(1-\sigma)(w \bar{L}+r \bar{K})
$$

where $w$ and $r$ denote the wage rate and the rental rate of capital, respectively. Moreover, $\bar{L}$ and $\bar{K}$ are fixed stocks of of labor and capital. Note that income inequality increases with $\sigma$. If $\sigma=1 / 2(\sigma=1)$, there is perfect income equality (inequality). ${ }^{6}$

Assuming that the non-status good is the numeraire good, letting $p$ denote the price of the status good, and recalling that each group has a unit mass, we obtain the status good demand functions as:

$$
\begin{array}{r}
S^{R}(p, \sigma, w, r, \bar{L}, \bar{K})=\frac{\sigma(w \bar{L}+r \bar{K})}{2 p} \\
S^{P}(p, \sigma, w, r, \bar{L}, \bar{K})=\frac{(1-\sigma)(w \bar{L}+r \bar{K})}{p[1+2(1-\sigma)]}
\end{array}
$$

where $S^{j}$ denotes equilibrium consumptions of the status good by group $j=R, P$. Consequently, aggregate equilibrium consumption of the status good is given by:

$$
\tilde{S}(p, \sigma, w, r, \bar{L}, \bar{K})=\frac{\sigma(w \bar{L}+r \bar{K})}{2 p}+\frac{(1-\sigma)(w \bar{L}+r \bar{K})}{p[1+2(1-\sigma)]}
$$

\footnotetext{
${ }^{4}$ It can be shown that for our specific functional form, when $y_{i}<\bar{y}, d U_{i}^{*} / d\left(\frac{y_{i}}{\bar{y}}\right)=\log N_{i}^{*}>0$. That is, falling behind hurts.

${ }^{5}$ As it turns out, our results are quite robust to alternative and perhaps more widely used utility functions. For example, our results would hold if we had used a CES-type utility function given by:

$$
U\left(N_{i}, S_{i}, \lambda_{i}\right)=f\left(\Lambda_{i}\right)\left[N_{i}^{\alpha}+\phi\left(\Lambda_{i}\right) S_{i}^{\alpha}\right]
$$

where $0<\alpha<1$ and the restrictions on $f($.$) and \phi($.$) are as above (see Marjit et al. (2015)).$

${ }^{6}$ While there may be disagreement on measurement of inequality in the literature, we use the simplest definition (i.e., the percentage of earned income). See Cowell and Flachaire (2017) for various measurements of inequality.
} 
The aggregate non-status consumption can be derived similarly. Next, we characterize the closed economy equilibrium.

\section{Autarky Equilibrium}

We first characterize the equilibrium of a closed economy by discussing two important properties of aggregate status good consumption. In addition to the intrinsic value of these properties, as we shall show shortly, they will be instrumental in determining the pattern of trade in an open economy setting.

Consider the impact of an increase in inequality on aggregate consumption of status good, ceteris paribus. The following result highlights that the aggregate consumption of status good is a non-monotonic function of inequality level.

Proposition 1. The relationship between the aggregate consumption of status good and the level of inequality, ceteris paribus, is inverted u-shaped. In particular, aggregate consumption of the status good peaks at $\sigma^{*}=(3-\sqrt{2}) / 2$ at any given price.

Proof. By differentiation equation (6) and simplifying, we obtain:

$$
\frac{\partial \widetilde{S}}{\partial \sigma}=\frac{w \bar{L}+r \bar{K}}{2 p(3-2 \sigma)^{2}}\left[(3-2 \sigma)^{2}-2\right]
$$

It follows from equation (7) that $\partial \widetilde{S} / \partial \sigma>(<) 0$ if and only if $\sigma<[3-\sqrt{2}] / 2(\sigma>[3-\sqrt{2}] / 2)$. In particular, $\partial \widetilde{S} / \partial \sigma=0$ if $\sigma^{*}=(3-\sqrt{2}) / 2$.

The intuition behind this result is interesting. A redistribution of income from the rich class to the poor would have different effect on status good depending the initial distribution. If the poor are too poor $\left(\sigma>\sigma^{*}\right)$, then a small redistribution of income from rich to poor (i.e., a small reduction in $\sigma$ ) will increase the consumption of status good. Such a small income redistribution reduces the consumption of status good by the rich since their income falls. However, the rise in consumption of this good by the poor class (due to such a type of income redistribution) is more than enough to offset its reduction by the rich. Thus, the aggregate consumption of status good rises. The converse is true when poor are not too poor (i.e., $\sigma<\sigma^{*}$ ). That is, an equal small income redistribution from the rich to the poor class will cause a bigger increase in consumption of status good by the poor class if the poor class are "too poor" than when they are "not-so-poor." This is because the farther away the poor are from the average, the "unhappier" they are and 
hence the "very poor" are likely to spend more resources in "soothing" their psychological pain of relative deprivation compared to the "not-so-poor." Consequently, when the poor are "not-sopoor" ("too poor"), the decrease in status consumption of the rich outweighs (is outweighed by) the increase in status consumption of the poor. In other words, when the level of preexisting inequality is low (high), a small fall in inequality will cause aggregate status consumption to fall (rise). Therefore, the relationship between consumption of status good and the level of inequality is inverted U-shaped.

Next, consider the relation between aggregate demand for status good and its price. Suppose there is an increase in price of status goods. Apart from price affecting demand for the status good via the standard substitution and income effects, it influences demand for the status good through two additional channels. First, price changes the factor prices (an important point to which we return shortly) and this in turn affects income of the two groups of consumers. This is an additional income effect that arises due to the general equilibrium aspect of our setup and its ownership structure of the production factors. Second, price impacts the relative income which in turn has implications for status good via function $\phi($.$) . However, this effect is limited$ to the poor. Due to these additional channels through which price influences aggregate status good consumption, the relation between price and demand for the status good is ambiguous. Let $\varepsilon^{j} \equiv\left(\partial y^{j} / \partial p\right)\left(p / y^{j}\right)$ be price (of status good) elasticity of income for income group $j=, P, R$. As it turns out, this elasticity plays a crucial role in ensuring a well-behaved aggregate demand for status good. The following result establishes a sufficient condition for price to have a negative impact on status good consumption.

Proposition 2. Aggregate demand for status good is decreasing in its price if $\varepsilon^{j}<1, j=P, R$.

Proof. Differentiate equation (4) with respect to $p$, use equation (3), and our definition of income elasticity to obtain:

$$
\frac{d S^{R}}{d p}=\frac{y^{R}}{2 p^{2}}\left(\varepsilon^{R}-1\right)
$$

implying that $\partial S^{R} / \partial p<0$ if $\varepsilon^{R}<1$. Similarly, it can be shown from equations (3) and (5) that $\partial S^{P} / \partial p<0$ if $\varepsilon^{P}<1$. Then, the statement of this proposition directly follows from equation $(6)$.

Given that consumption level for status good is not monotonic in changes in income inequality, it is interesting to study how prices behave in this economy with respect to a change in income inequality. Suppose that initially $\sigma<\sigma^{*}$ and consider a small increase in inequality, ceteris 
paribus. Since there is no change in factor endowment and production technologies but the consumption of status good (thus its production) rises due to Proposition 1 (a shift in demand and a movement along the supply for this good), $p$ must rise. In other words, the demand for status good shifts up while its supply function is unchanged, leading to an increase in its price. The converse it true if $\sigma>\sigma^{*}$. Thus we have the following result.

Proposition 3. The price of status good is increasing (decreasing) in the level of inequality $\sigma$ if $\sigma<\sigma^{*}\left(\sigma>\sigma^{*}\right)$

Next, consider the effects of an increase in inequality on factor prices. Again, start with a case where $\sigma<\sigma^{*}$. It directly follows form Proposition 3 and Stolper-Samuelson Theorem that an infinitesimally small increase in $\sigma$ will increase $r / p$ and lower $w / p$. Moreover, the opposite is true if $\sigma>\sigma^{*}$. Therefore, we highlight the following results.

Proposition 4. The real return to capital (labor) is increasing (decreasing) in income inequality if $\sigma<\sigma^{*}$. The converse is true if $\sigma>\sigma^{*}$.

\section{Trading equilibrium and pattern of trade}

Now suppose that there are two countries: Country 1 and Country 2. We use superscripts to denote countries. Assume that Country 1 has a more equal income distribution than Country 2, i.e., $\sigma^{1}<\sigma^{2}$. Maintain that both countries have identical factor endowments and technology. As such, the supply curve for the status (and non-status good) that each country faces is the same. Assuming that the sufficient condition given by Proposition 2 holds, each country faces a downward sloping aggregate demand curve. It follows from Proposition 1 that Country 2 faces a higher (lower) demand for status good than Country 1 does if $\sigma^{1}<\sigma^{2}<\sigma^{*}\left(\sigma^{*}<\sigma^{1}<\sigma^{2}\right)$. Proposition 3 implies that the relative price of status good would be higher in Country 2 than in Country 1 at autarky equilibrium (i.e., $p^{2}>p^{1}$ ) if preexisting levels of inequality in both countries are sufficiently low. Conversely, this relative price will be higher in Country 1 than Country 2 if preexisting levels of inequality in both countries are sufficiently high. Finally, directly following from Proposition 4, we have $r^{2}>r^{1}$ and $w^{1}>w^{2}$ if $\sigma^{1}<\sigma^{2}<\sigma^{*}$ at autarky equilibrium.

Consider the case that inequality is higher in country 2, but measure of inequality in both countries are lower than the threshold level, i.e., $\sigma^{1}<\sigma^{2}<\sigma^{*}$. Maintain that the condition of Proposition 2 also holds. If these countries open up their economies to trade, Country 1 exports (imports) status good (non-status good) and Country 2 exports (imports) non-status 
good (status good) since relative price of status good is lower in Country 1 than in Country 2 at autarky. The opposite pattern of trade emerges if $\sigma^{*}<\sigma^{1}<\sigma^{2}$. We highlight this result in the following proposition.

Proposition 5. Let $\varepsilon^{j}<1, j=P, R$. Assuming free trade, Country 1 will export (import) status good (non-status good) while Country 2's pattern of trade will be the opposite if $\sigma^{1}<\sigma^{2}<\sigma^{*}$. The converse patterns of trade will occur if $\sigma^{*}<\sigma^{1}<\sigma^{2}$.

Recall that production sides of these two economies are identical and neither have comparative advantage in production of any good. Yet, inter-industry trade takes place between them due to demand differences for status good arising from higher level of inequality in one country than the other. It is also straightforward to see that the pattern of trade as characterized in the proposition hold if $\sigma^{*}<\sigma^{2}<\sigma^{1}\left(\sigma^{2}<\sigma^{1}<\sigma^{*}\right)$. That is, due to symmetry, Country 1 (2) exports status good if $\sigma^{*}<\sigma^{2}<\sigma^{1}\left(\sigma^{2}<\sigma^{1}<\sigma^{*}\right)$.

Figures 1 and 2 show the open economy equilibria when the countries have sufficiently low and sufficiently high levels of income inequality respectively. The world average supply curve is same as the individual supply curves, i.e., $Y_{S}^{1}=Y_{S}^{2}=Y_{S}$ since there are no supply side differences between the countries. The aggregate demand curves for the two countries are given by $Y_{D}^{1}$ and $Y_{D}^{2}$ respectively and the world average demand curve is given by $Y_{D}=\left(Y_{D}^{1}+Y_{D}^{2}\right) / 2$. The intersection of the average supply and demand curves determine the free trade equilibrium (relative) price and quantity of status good which we denote as $p^{W}$ and $\widetilde{S}^{W}$ respectively. After trade is opened up, price of status good, as well as rental-wage ratio falls in Country 2 and rises in Country 1 when the preexisting levels of inequality in the two countries are sufficiently low and the opposite happens when the countries are characterized by sufficiently high levels of inequality to start with. Thus, when the levels of preexisting inequality are low in both the countries, Country 2 exports the non-status good and imports the status good and Country 1 does the opposite. However, when the preexisting levels of inequality are high in the two countries, Country 1 exports the non-status good and imports the status good and Country 2 does the opposite.

At a first glance, it may seem that the pattern of trade is indeterminate if both countries have 'large' enough difference in their levels of inequality. However, a more careful examination of our model reveals a complete characterization of trade pattern. ${ }^{7}$ To show this, consider the effects of various combination of $\sigma^{1}$ and $\sigma^{2}$ on the demand for status good and its price differential in these

\footnotetext{
${ }^{7}$ We are particularly grateful to an anonymous referee for bringing this to our attention.
} 


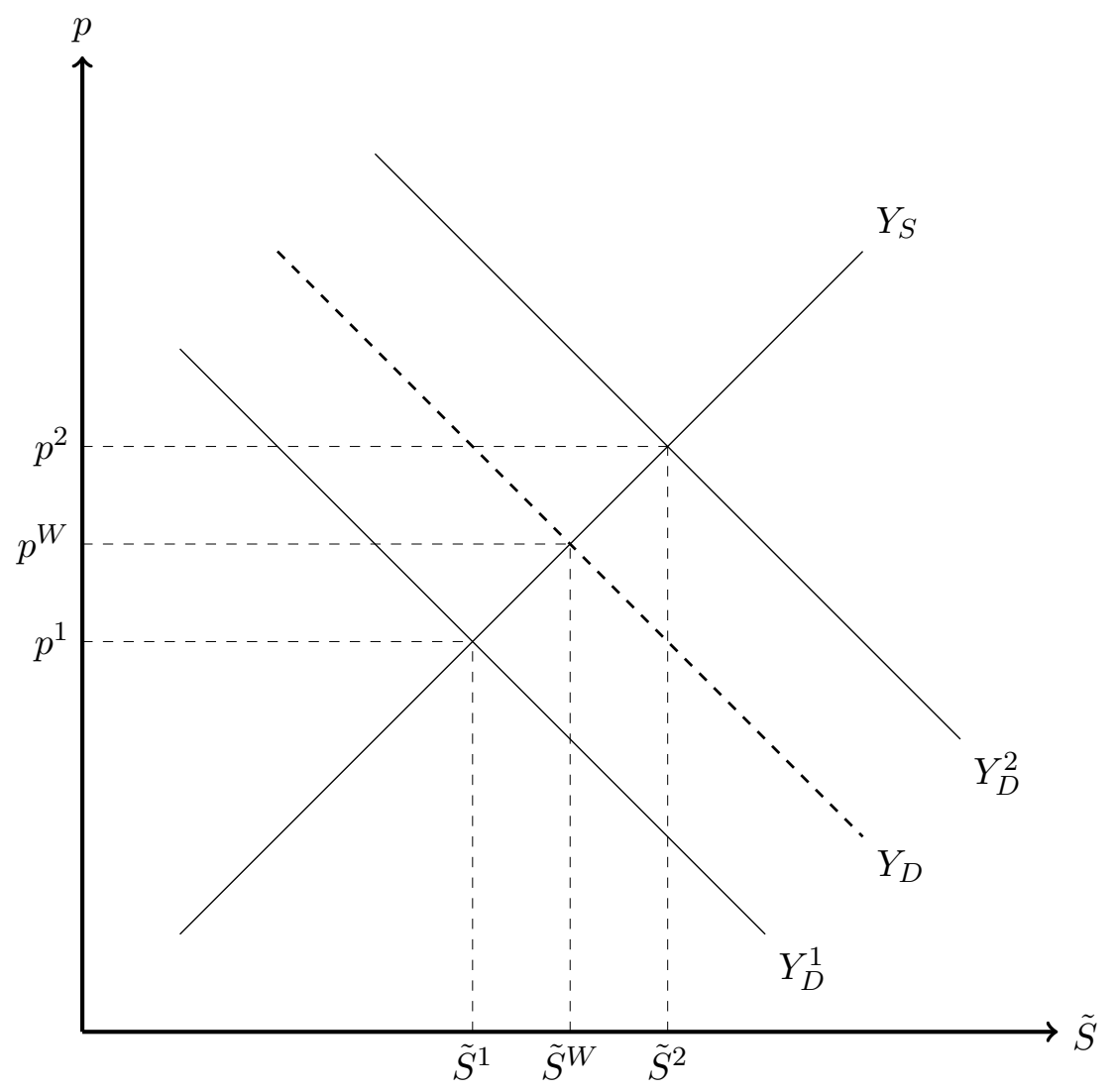

Figure 1: $\sigma^{1}<\sigma^{2}<\sigma^{*}$

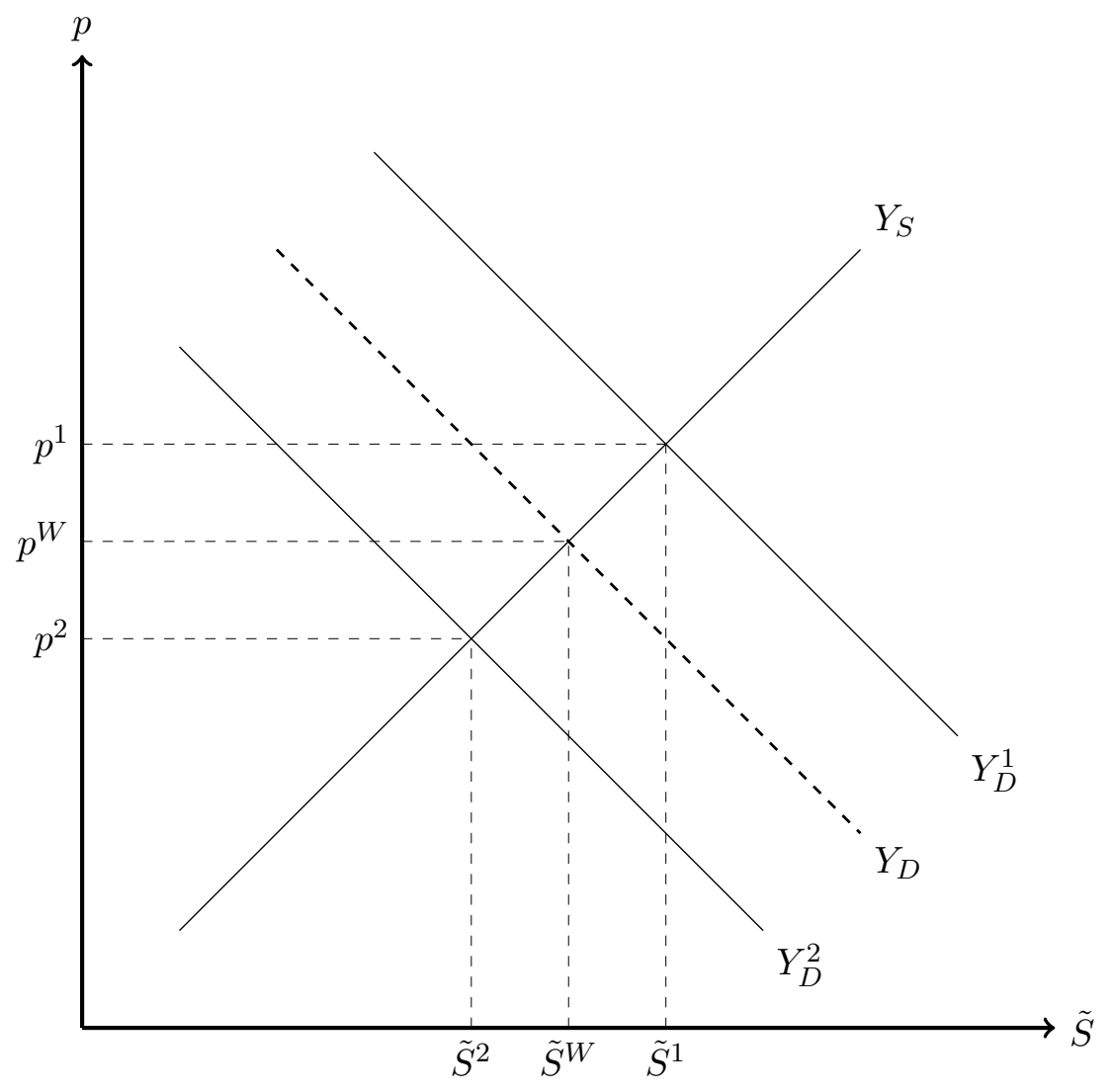

Figure 2: $\sigma^{*}<\sigma^{1}<\sigma^{2}$ 
countries. Suppose that $\sigma^{1}=\sigma^{2}=\sigma^{*}$. It directly follows from equation (6) that the demand for status good is the same in both countries and so is its price. Now, let $\sigma^{1}$ decrease from $\sigma^{*}$. Then, it follows form Proposition 1 that the demand for status good decreases in Country 1. On the other hand, demand for status good also decreases in Country 2 if $\sigma^{2}$ increases from $\sigma^{*}$. Hence, for any $\sigma^{1}<\sigma^{*}$, there is an associated level of $\sigma^{2}>\sigma^{*}$ at which the demand for status good and its price are the same in both countries. In particular, as is directly evident form equation (6), the demand for status good is the same in both countries if $\sigma^{1}=1 / 2$ and $\sigma^{2}=1$. Symmetry also dictates that such a relation ship holds for $\sigma^{1}>\sigma^{*}$, i.e., for any $\sigma^{1}>\sigma^{*}$, there is an associated level of $\sigma^{2}<\sigma^{*}$ for which demand for status good and its price would be the same in both countries. Denote such $\sigma^{1}$ and $\sigma^{2}$ loci by $\sigma^{2}=\xi\left(\sigma^{1}\right)$. That is, if $\sigma^{2}=\xi\left(\sigma^{1}\right)$, then the autarky price of the status good is equal in both countries. It also follows from Proposition 1 that $p^{1}<p^{2}$ at autarky if $\sigma^{*}<\sigma^{2}<\xi\left(\sigma^{1}\right)$ where $\sigma^{1}<\sigma^{*}$ or if $\sigma^{*}>\sigma^{2}>\xi\left(\sigma^{1}\right)$ where $\sigma^{1}>\sigma^{*}$. Conversely, $p^{1}>p^{2}$ at autarky if $\sigma^{2}>\xi\left(\sigma^{1}\right)$ where $\sigma^{1}<\sigma^{*}$ or if $\sigma^{2}<\xi\left(\sigma^{1}\right)$ where $\sigma^{1}>\sigma^{*}$. Hence, we have the following result.

Proposition 6. Assume $\varepsilon^{j}<1, j=P, R$. At free trade, Country 1 (2) will export status good (non-status good) if (i) $\sigma^{*}<\sigma^{2}<\xi\left(\sigma^{1}\right)$ where $\sigma^{1}<\sigma^{*}$; or (ii) $\sigma^{*}>\sigma^{2}>\xi\left(\sigma^{1}\right)$ where $\sigma^{1}>\sigma^{*}$. Conversely, Country 2 (1) will export status good (non-status good) if (i) $\sigma^{2}>\xi\left(\sigma^{1}\right)$ where $\sigma^{1}<\sigma^{*}$; or (ii) $\sigma^{2}<\xi\left(\sigma^{1}\right)$ where $\sigma^{1}>\sigma^{*}$

Figure 3 presents our characterization of trade pattern schematically, where relationship $\sigma^{2}=\xi\left(\sigma^{1}\right)$ is shown by curve $\xi e \xi^{\prime}$. Proposition 5 addresses scenarios where $\sigma^{1}$ and $\sigma^{2}$ belong to areas $A, B, A^{\prime}$ and $B^{\prime}$. Country 1 exports the status good if $\sigma^{1}$ and $\sigma^{2}$ belong to area $A$ and Country 2 exports this good if the inequality levels are in area $B$. Note that the level of inequality is higher in Country 2 than in Country 1 under both of these scenarios. i.e., $\sigma^{1}<\sigma^{2}$. Due to symmetry, Proposition 5 also implies that Country 1 exports the status good in area $A^{\prime}$ whereas Country 2 exports this good if inequality parameters fall in area $B^{\prime}$. Proposition 6 addresses scenarios where $\sigma^{1}$ and $\sigma^{2}$ fall in areas $C, D, C^{\prime}$ and $D^{\prime}$. Consider areas $C$ and $D$. Recall that for all combinations of $\sigma^{1}$ and $\sigma^{2}$ along $\xi e \xi^{\prime}$ autarky price of the status good is equal across both countries, whereas the price of this good is lower in Country 1 (2) if these inequity parameters are in area $C(D)$. Therefore, Country 1 (Country 2) exports the status good in area $C(D)$. The same trade pattern as in $C$ and $D$ emerges in areas $C^{\prime}$ and $D^{\prime}$. 


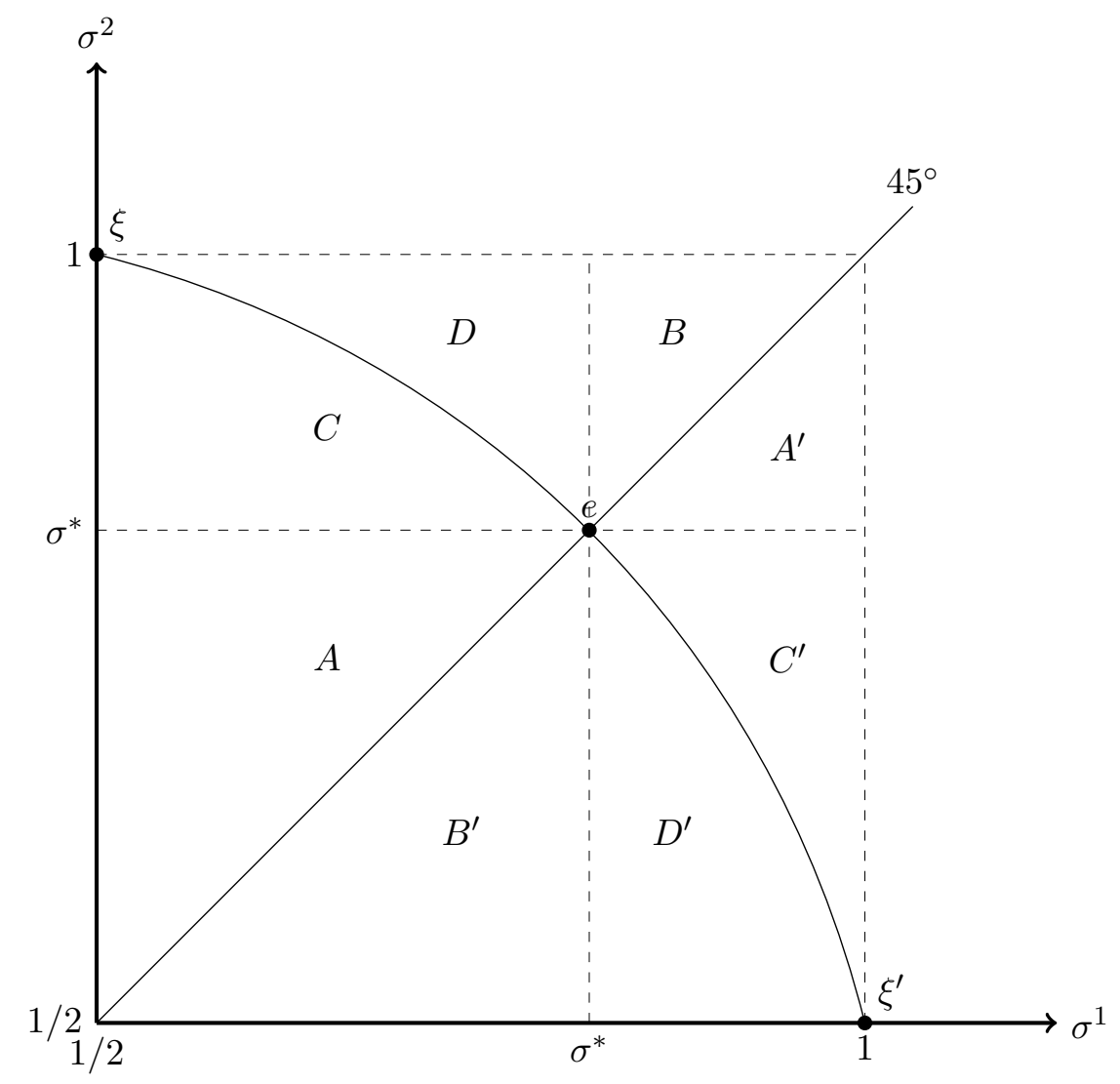

Figure 3: Trade Pattern and combinations of $\sigma^{1}$ and $\sigma^{2}$

\section{Conclusion}

We incorporate demand side differences across countries, arising from cross-country preference differential toward status goods due to varying degree of income inequality, in a standard model of international trade assuming that these countries have identical production sides. We base our formulation of preferences on insights from behavioral economics and social psychology. We show how differences in preexisting levels of inequality across countries may be a basis for international trade and may determine the pattern of trade when individual preferences are non-homothetic. Although our model is stylized, it offers a new simple and elegant setup that may explain trade between countries in absence of supply side differences.

As an extension of our model, one may consider a monopolistic competitive setup (as in Oladi and Gilbert, 2011, Gilbert et al., 2015, and Pi and Zhou, 2015) where there is continuum of goods that could be ordered by status ranking. This is likely to yield very detailed predictions concerning trade patterns. Our theory may also guide empiricists to study bilateral trade in status goods between countries with different levels of income distribution. Most importantly, our paper is agnostic with regard to sources of inequality (i.e., the reason why $\sigma$ may be different 
across countries). Recall that the aggregate income is the same in both countries under free trade. Hence, it may not be straightforward why income distributions differ between these countries. One may extend our model to exploit the micro structure of inequality and its effects on trade pattern. For example, one may assume a particular combination of factor ownership by inhabitants in each country, as in Mayer (1984), that potentially gives rise to differing degree of inequality between these two countries, while resulting in the same level of aggregate income for both countries. $^{8}$

\footnotetext{
${ }^{8}$ We are grateful to an anonymous referee for bringing this to our attention.
} 


\section{References}

Bagwell, L.S. and B.D. Bernheim, (1996), "Veblen Effects in a Theory of Conspicuous Consumption," American Economic Review 86: 349-73.

Beggan, J. K. (1992), "On the Social Nature of Nonsocial Perception: The Mere Ownership Effect," Journal of Personality and Social Psychology, 62: 229-237.

Blanchflower, D. G. and A.J. Oswald, (2004), "Well-being over Time in Britain and the USA," Journal of Public Economics 88: 1359-1386.

Chakrabarti, A. (2000), "Does Trade Cause Inequality?" Journal of Economic Development 25: $1-22$.

Clark, A.E., Frijters, P. and M.A. Shields, (2008), "Relative Income, Happiness, and Utility: An Explanation for the Easterlin Paradox and Other Puzzles," Journal of Economic Literature 46: $95-144$.

Cowell, F.A. and E. Flachaire (2017), "Inequality with Ordinal Data," Economica 84: 290-321.

Davis, D.R., (1998), "Critical Evidence on Comparative Advantage? North-North Trade in a Multilateral World," Journal of Political Economy 105: 1051-1060.

Duesenberry, J. S. (1949), Income, Saving and the Theory of Consumer Behavior, Cambridge: Harvard University Press.

Dwibedi, J. K. and S. Marjit (2017), "Relative Affluence and Child Labor-Explaining a Paradox," Review of Development Economics 21: 1178-1190.

Ferrer-i-Carbonell, A. (2005), "Income and Well Being: An Empirical Analysis of the Comparison Income Effect," Journal of Public Economics 89: 997-1019.

Frank, R.H. (1985), "The Demand for Unobservable and Other Non-positional Goods," American Economic Review, 75: 101-116.

Gilbert, J., Beladi, H. and R. Oladi (2015), "North-South Trade Liberalization and Economic Welfare," Review of Development Economics 19: 1006-1017.

Grossman, G. M. and E. Rossi-Hansberg (2012), "Task Trade between Similar Countries," Econometrica 80: 593-629. 
Grossman, G. M. and C. Shapiro (1988), "Foreign Counterfeiting of Status Goods," Quarterly Journal of Economics 103: 79-100.

Helpman, E. (1981), "International Trade in the Presence of Product Differentiation, Economies of Scale and Monopolistic Competition: A Chamberlin-Heckscher-Ohlin Approach," Journal of International Economics, 11, 305-340.

Hollander, H. (2001), "On the Validity of Utility Statements: Standard Theory versus Duesenberry's," Journal of Economic Behavior and Organization 45: 227-249.

Hunter, L. C. (1991), "The Contribution of Nonhomothetic Preferences to Trade," Journal of International Economics 30: 345-58.

Jones, R.W., (1965), "The Structure of Simple General Equilibrium Models," Journal of Political Economy 73: 557-572.

Krugman, P.R. (1979), "Increasing Returns, Monopolistic Competition, and International Trade," Journal of International Economics 9: 469-79.

Marjit, S., Santra, S. and K.K. Hati (2015), "Relative Social Status and Conflicting Measures of Poverty: A Behavioral Analytical Model," Journal of Quantitative Economics 13: 77-86.

Markusen, J. (1986), "Explaining the Volume of Trade: An Eclectic Approach," American Economic Review 76: 1002-1011.

Mayer, W. (1984), "Endogenous Tariff Formation," American Economic Review 74: 970-985.

Mitra, D. and V. Trindade, (2005), "Inequality and Trade," Canadian Journal of Economics 38: $1253-1271$.

Oladi, R. and J. Gilbert (2011), "Monopolistic Competition and North-South Trade," Review of International Economics 19: 459-474.

Pi, J. and Y. Zhou (2015, "International Factor Mobility, Production Cost Components, and Wage Inequality," BE Journal of Economic Analysis 63 Policy 15 (2): 503-522.

Rucker, D. D. and A.D. Galinsky (2008), "Desire to Acquire: Powerlessness and Compensatory Consumption," Journal of Consumer Research 35: 257-267. 
Sivanathan, N. and N.C. Petit (2010), Protecting the Self through Consumption: Status Goods as Affirmational Commodities, Journal of Experimental Social Psychology 46: 564-570.

Thursby, J. G. and M. C. Thursby (1987), "Bilateral Trade Flows, the Linder Hypothesis, and Exchange Risk," Review of Economics and Statistics 6: 488-495

Weiss, Y. and Fershtman, C. (1998), Social Status and Economic Performance: A Survey, European Economic Review 42: 801-820. 